\title{
Digestibility of proteins of the histological components of cooked and raw rice
}

\author{
BY J. HOWARD BRADBURY, J. GRANT COLLINS* \\ AND N. A. PYLIOTIS † \\ Chemistry Department, Australian National University, \\ Canberra, ACT 2600, Australia
}

(Received 3 January 1984 - Accepted 3 July 1984)

1. The aleurone layer, grain coat and embryo which constitute rice bran are rich in vitamins, lipids, protein and lysine compared with the endosperm (milled rice).

2. A method was developed to measure the in vitro protein digestibility of raw and cooked brown rice and their histological components.

3. The protein digestibility of cooked endosperm by the in vitro method agreed with that of other workers using in vivo techniques.

4. The protein digestibility of the aleurone layer and grain coat from raw rice was only $25 \%$ but increased to $65 \%$ from cooked rice, due to disruption of the cellulosic cell walls at $100^{\circ}$, which was shown by electron microscopy.

5. The decreased protein digestibility due to cooking was not the result of formation of $\epsilon$-lysyl- $\gamma$-glutamyl isopeptide cross-links, but may be due to formation of a cystine-rich core that is resistant to proteases.

6. The protein digestibility of cooked brown rice was approximately the same as that of cooked milled rice, hence it is advantageous for those for whom rice is a staple food to consume brown rather than milled rice.

Rice supplies a large proportion of the protein intake for many millions of people (Pereira et al. 1981) and there has therefore been considerable interest in both the quantity and quality of protein in the rice grain. Rice containing an increased proportion of protein (high-protein rice) has been developed by the International Rice Research Institute (IRRI) and the distribution of the protein between the various histological components has been determined, as well as the amino acid profile (Bradbury et al. 1980a,b). The increased content of protein and of the first limiting amino acid lysine in the aleurone layer and germ, as compared with the endosperm, shows the importance of the bran layer as a protein source, particularly for those millions of people in South and South-east Asia for whom rice is the staple food. The question arose, however, of the possible decreased digestibility of the proteins of the bran layer as compared with the endosperm proteins. This is the question which is addressed in the present paper, for cooked and uncooked rice components.

Because of the difficulty of obtaining large amounts of well-characterized aleurone layer plus grain coat and other histological components by the methods that we have developed (Bradbury et al. 1980a), it was necessary to use an in vitro digestion system. Various enzyme systems have been used including pepsin (EC 3.4.23.1) followed by pancreatin (Akeson \& Stahman, 1964), an enzyme preparation from Streptomyces griseus (Ford \& Salter, 1966), papain (EC 3 . 4.23 2) (Buchanan \& Byers, 1969) and a multi-enzyme system using trypsin (EC 3 4.21 .4), chymotrypsin (EC 3.4.21 .1) and peptidase (Hsu et al. 1977). Büchmann (1979) studied the protein digestibility of six cereals including rice using a pepsin-pancreatin system with trichloroacetic acid (TCA) precipitation of large polypeptides after the incubation step. With the exception of barley, Büchmann (1979) concluded that this method gave unsatisfactory results. As part of the present study, it was therefore necessary to

Present addresses: " Department of Biochemistry, University of New South Wales, Kensington, NSW, Australia. † Prince Henry's Hospital, St Kilda Road, Melbourne, Victoria, Australia. 
develop an in vitro technique that would give satisfactory results. A prime consideration was that the technique should model, as closely as possible, physiological conditions. A two-step digestion using pepsin followed by trypsin, chymotrypsin, carboxypeptidase and elastase was found to be satisfactory.

\section{MATERIALS AND METHODS}

\section{Materials}

The rices used were IRRI varieties IR-32 and a high-protein selection IR-480-5-9. Pepsin, trypsin, $\alpha$-chymotrypsin, elastase (EC 3 .4 21 .11) and carboxypeptidase-B $(E C$ 3 .4 .17.2) were obtained from Worthingon Biochemicals, New Jersey, USA. Ribonuclease-A (EC 3 1.27.5) and casein were obtained from Sigma Chemicals, St Louis, USA.

\section{Methods}

The IR-32 and IR-480 whole-grain samples were crushed in a Waring blender then further powdered in a mortar and pestle to be fine enough to pass through a 36 mesh $(420 \mu \mathrm{m})$ sieve. The endosperm, aleurone plus grain coat and embryo were prepared as previously described (Bradbury et al. 1980a), except that the aleurone plus grain coat was not washed in a graded alcohol series. The endosperm was crushed and sieved as described previously, but the aleurone plus grain coat $(100 \mathrm{mg})$ and embryo were not crushed before digestion.

Cooked rice. Rice (IR-32) was placed in boiling water for 30 min after which the water was decanted, the residue centrifuged off and the supernatant fraction lyophilized. The boiled, histological components were removed from the boiled whole grain and the samples dried in a vacuum desiccator over silica gel for $16 \mathrm{~h}$. The dried whole grain and endosperm were crushed and sieved as before.

Preparation and purification of glutelin. Glutelin was prepared by extraction of the rice powder with a $0.05 \mathrm{M}$-sodium hydroxide solution after removal of the albumins and globulins as described by Cagampang et al. (1976). The glutelin was further purified according to the methods of Sawai \& Morita (1968).

Pepsin digestion. Finely crushed rice (IR-32; $3 \mathrm{~g}$ ) and $1.5 \mathrm{mg}$ pepsin were added to $10 \mathrm{ml}$ hydrochloric acid solution at $\mathrm{pH} 1.5$. The solution was stirred for $3 \mathrm{~h}$ at $37^{\circ}$ and, periodically, a small amount of concentrated $\mathrm{HCl}$ was added to maintain the $\mathrm{pH}$ at approximately 1.6 . The sample was centrifuged for $15 \mathrm{~min}$ at $2^{\circ}$ and the supernatant fraction decanted. $\mathrm{NaOH}(2 \mathrm{M})$ was added to the supernatant fraction until the $\mathrm{pH}$ reached 10 , and the sample centrifuged for $10 \mathrm{~min}$ at $500 \mathrm{~g}$ to remove the precipitate. The supernatant fraction was decanted and lyophilized. The lyophilized material was weighed and analysed for nitrogen, and a fraction was dialysed against distilled water. The material inside and outside the dialysis bag was lyophilized and weighed, and $\mathbf{N}$ determined. Amino acid analyses of the lyophilized material before and after dialysis were made. The dialysis tubing had an experimentally determined cut-off limit of 5000-6000 molecular weight.

Two-stage digestion. Rice (IR-32; $1.5 \mathrm{~g}$ ) which was finely crushed was placed in a jacketed flask at $37^{\circ}$ and $1.5 \mathrm{mg}$ pepsin dissolved in $9 \mathrm{ml} \mathrm{HCl}(\mathrm{pH} \mathrm{1.5)}$ was added. The suspension was stirred for $3 \mathrm{~h}$ after which $100 \mathrm{mg}$ sodium bicarbonate was added and the $\mathrm{pH}$ adjusted to 8 with $2 \mathrm{M}-\mathrm{NaOH}$ (Davenport, 1961). Based on the values of Rinderknecht $e t$ al. (1978) for the mean concentration in pancreatic juice, trypsin $(2.75 \mathrm{mg}), \alpha$-chymotrypsin $(1.3 \mathrm{mg})$, elastase $(0.2 \mathrm{mg})$ and carboxypeptidase- $\mathrm{B}(0.3 \mathrm{mg})$ were added and the $\mathrm{pH}$ adjusted to 8.2 . The suspension was stirred for $16 \mathrm{~h}, 2 \mathrm{ml}$ freshly-prepared TCA $(120 \mathrm{~g} / \mathrm{l})$ added to it and the mixture stirred for $5 \mathrm{~min}$. The mixture was centrifuged at $10000 \mathrm{~g}$ for $30 \mathrm{~min}$, the residue washed once with water and the washings and supernatant fraction filtered. The filtrate was made slightly alkaline with $2 \mathrm{M}-\mathrm{NaOH}$, and lyophilized. The lyophilized material (the digest) 
Table 1. Digestion of uncooked whole brown rice (IR-32) by pepsin at pH 1.6 and $37^{\circ}$

\begin{tabular}{lll}
\hline \hline & \multicolumn{2}{c}{ Pepsin digestion } \\
\hline $\begin{array}{c}\text { Percentage of total nitrogen solubilized at } \\
\mathrm{pH} 1.6 \text { with no pepsin present (control) }\end{array}$ & 18 & $3.0 \mathrm{~g}$ rice \\
$\begin{array}{c}\text { Percentage of total N solubilized by } \\
\text { pepsin treatment }\end{array}$ & 49 (SD 2) & 42 (SD 2) \\
Proportion of solubilized N dialysible & 0.70 & 0.54 \\
Proportion of solubilized N non-dialysible & 0.30 & 0.46 \\
\hline
\end{tabular}

was analysed for N. For digestion of the histological components where only small quantities $(100 \mathrm{mg})$ of sample were available, the whole procedure was scaled down accordingly. All $\mathrm{N}$ analyses were carried out four times on a single sample and all reported digests are averages of at least two runs; average standard deviation approximately $2 \%$.

Cyanoethylation. Glutelin $(11 \mathrm{mg})$ was dissolved in $1 \mathrm{ml} 8 \mathrm{M}$-urea, and $20 \mu \mathrm{l}$ redistilled acrylonitrile and $20 \mu 1$ redistilled triethylamine were added. After $104 \mathrm{~h}$ treatment at $37^{\circ}$, the solution was dialysed against water and the solvent removed by passing a stream of $\mathrm{N}_{2}$ over the suspension at $50^{\circ}$. The elution position of $\epsilon$-carboxyethyl-lysine on the amino acid analyser was obtained after cyanoethylation of trilysine followed by hydrolysis with $6 \mathrm{M}-\mathrm{HCl}$.

Amino acid analyses. All samples were analysed on a Technicon Amino Acid Analyzer using a $700 \mathrm{~mm}$, type C-2 resin, ion-exchange column (Bradbury et al. 1980a, b).

\section{RESULTS}

The results of the pepsin digestion given in Table 1 show that about $45 \%$ of the total protein was solubilized, compared with only $18 \%$ in the control experiment in the absence of pepsin. The reduction in the ratio, pepsin:substrate from $1.5 \mathrm{mg}: 1.5 \mathrm{~g}$ to $1.5 \mathrm{mg}: 3.0 \mathrm{~g}$ (Table 1) reduced the amount of solubilization from 49 to $42 \%$ and also reduced the proportion of dialysible material from $0 \cdot 70$ to $0 \cdot 54$.

The amino acid analysis of the dialysible unhydrolysed material following pepsin digestion showed that few free amino acids were liberated, hence pepsin digestion mainly breaks the protein down into peptides and polypeptides. The amino acid analysis of the total $\mathrm{N}$ solubilized from $3 \mathrm{~g}$ rice (Table 1) showed that levels of serine, proline and valine decreased while levels of aspartic acid, glycine, tyrosine and arginine increased compared with the analysis of IR-32 brown rice (Bradbury et al. 1980a). The amino acid analysis of the dialysible material from $3 \mathrm{~g}$ rice showed the almost complete absence of cystine, whilst that of the non-dialysible material was high in cystine. It appears that virtually all the cystine solubilized by the pepsin digestion had remained as non-dialysible large polypeptides and native protein.

The results of the two-stage digestion using pepsin at $\mathrm{pH} 1.5$ followed by trypsin, chymotrypsin, elastase and carboxypeptidase- $\mathrm{B}$ at $\mathrm{pH} 8$ are given in Table 2. As glutelin accounts for about $85 \%$ of the endosperm protein (Sawai \& Morita, 1968) the digestion was carried out on glutelin and also on glutelin that had been refluxed as a suspension in water for $30 \mathrm{~min}$ before digestion. The digestibilities in these two cases were 97 and $87 \%$ 
Table 2. Digestion of rice and its histological components in the two-stage digestion process (pepsin followed by pancreatic enzymes*)

(Mean values for duplicate analyses)

Percentage of total nitrogen digested $\dagger$ to peptides and amino acids in two-stage digestion process for

\begin{tabular}{lcccc}
\cline { 2 - 4 } \multicolumn{1}{c}{$\begin{array}{c}\text { Sample of } \\
\text { rice }\end{array}$} & $\begin{array}{c}\text { Whole } \\
\text { brown rice }\end{array}$ & Endosperm & $\begin{array}{c}\text { Aleurone layer }+ \\
\text { grain coat }\end{array}$ & Embryo \\
\hline IR-32 (raw) & $73 \ddagger$ & 79 & 25 & 47 \\
IR-32 (cooked) & 68 & 70 & 65 & 58 \\
IR-480 (raw) & $68 \S$ & - & - & - \\
\hline
\end{tabular}

* For details, see p. 508.

$\dagger$ Under the conditions of the experiment casein was found to be $89 \%$ digested, which agreed exactly with the result obtained by Roxas et al. (1979) in an in vivo study.

$\ddagger$ Deletion of trichloroacetic acid (TCA) precipitation gave a value of $82 \%$. A two-fold increase in the amount of substrate used and deletion of the TCA precipitation gave a value of $74 \%$.

$\S$ A two-fold increase in the amount of solution and hence a doubling of the amounts of enzymes in both stages gave a value of $82 \%$.

respectively; the reduction caused by heat treatment corresponded with that for endosperm in Table 2.

Several variations in the two-stage process brought about by altering the enzyme:substrate ratio and the elimination of the TCA-precipitation step are described in Table 2 and show the versatility of the in vitro method. The elimination of the TCA step allowed polypeptides and proteins of molecular weight greater than about 10000 to be included (clearly an undesirable feature) and this caused an increase of about $10 \%$ in the value of $\mathrm{N}$ digested in both cases.

The most interesting feature of the results shown in Table 2 is the very low digestibility of the proteins of aleurone cells plus grain coat prepared from raw rice and the great increase brought about by boiling the rice before removing the aleurone layer plus grain coat. The explanation of this result is shown in Plate 1, which is an electron micrograph of part of a treated rice grain examined using procedures described previously (Bradbury et al. 1980a). The heat treatment clearly caused disruption of the cellulosic cell walls of the aleurone layer. The proteolytic enzymes used in the two-stage digestion were unable to penetrate the cell walls of the aleurone layer of the raw rice, hence accounting for the low value in Table 2 of $25 \% \mathrm{~N}$ digested. However, after heat treatment, the aleurone proteins were available for proteolysis and this accounted for the increased value in Table 2. Other methods for causing disruption of aleurone cell walls and increased protein digestibility include treatment of raw rice with formic acid or pretreatment with cellulase $(E C 3.2 .1$.4).

Following boiling, the digestibilities of brown rice and of the endosperm (milled rice) were decreased (Table 2). In order to check whether the decreased digestibilities of the brown rice and of the endosperm due to boiling may have been due to the formation of isopeptide linkages between the $\epsilon$-amino group of lysine (which could not then be attacked by trypsin) and the $\gamma$-carboxyl group of glutamic acid residues (Bjarnason \& Carpenter, 1969, 1970; Waibel \& Carpenter, 1972) the following experiment was carried out. Glutelin was reacted with acrylonitrile, which reacted with the free lysine amino groups, followed by normal acid-hydrolysis and amino acid analysis (Pisano et al. 1969). Any isopeptide-linked lysine residues would be observed as free lysine residues on amino acid analysis. Only a trace 
Table 3. Amino acid analyses* (residues/ 1000 residues) of IR-32 brown rice and of digested material (two-stage process $\dagger$ ) from raw IR-480, raw IR-32 and cooked IR-32 rice

\begin{tabular}{lcccc}
\hline \multicolumn{3}{c}{ Amino acid } & \multicolumn{3}{c}{ Material digested from } & $\begin{array}{c}\text { Whole } \\
\text { brown rice } \\
\text { (IR-32) }\end{array}$ \\
\cline { 2 - 5 } & IR-480 rice & IR-32 rice & IR-32 (cooked) rice & 85 \\
Alanine & 100 & 90 & 96 & 61 \\
Arginine & 15 & 14 & 17 & 91 \\
Aspartic acid & 105 & 109 & 123 & 11 \\
Cystine & 13 & 14 & 5 & 162 \\
Glutamic acid & 173 & 192 & 136 & 89 \\
Glycine & 99 & 95 & 117 & 25 \\
Histidine & 22 & 24 & 23 & 86 \\
Isoleucine & 48 & 48 & 40 & 41 \\
Leucine & 100 & 86 & 86 & 16 \\
Lysine & 41 & 41 & 42 & 45 \\
Methionine & 7 & 18 & 17 & 63 \\
Phenylalanine & 48 & 48 & 43 & 35 \\
Proline & 53 & 56 & 68 & 23 \\
Serine & 33 & 28 & 41 & 74 \\
Threonine & 39 & 37 & 42 & 32 \\
Tyrosine & 28 & 26 & 72 & \\
Valine & 76 & 74 & & \\
\hline
\end{tabular}

* An additional peak occurred on the chromatogram between ammonia and lysine that was identified as ornithine and gave the following values (residues ornithine/1000 residues): IR-480, 67; IR-32, 58; IR-32 cooked, 62.

$\dagger$ For details, see p. 508.

amount $(<0.5 \mathrm{mmol} / \mathrm{mol})$ of lysine was found for glutelin and also for glutelin which had been treated at $100^{\circ}$ for $30 \mathrm{~min}$, hence there was no appreciable amount of isopeptide bond formation.

The amino acid composition of the material digested by the two-stage treatment with proteases is shown in Table 3. An interesting feature was the occurrence of considerable amounts of ornithine, together with a very low value for arginine. This results from the hydrolysis of arginine to ornithine which has been shown not to occur during the pepsin treatment in acid solution, and presumably, therefore, occurs during stage 2 of the enzyme treatment in slightly basic solution. The sum of the ornithine and arginine contents in Table 3 corresponds closely with the content of arginine of the $\mathrm{N}$-containing material digested in the acid pepsin treatment (Collins, 1981) and exceeds that of the brown rice. Other differences between the composition of the digested material in Table 3 and that of brown rice were increased amounts of aspartic acid, glycine and tyrosine and a decreased amount of serine in the digests.

\section{DISCUSSION}

The results in Table 2 show that raw brown rice was less digestible than raw white rice (endosperm), due to the lower digestibility of the protein contained in the bran layers (aleurone layer + grain coat). On cooking, the protein in the endosperm becomes less digestible while the protein in the bran layers becomes more accessible, hence more digestible. The thick cell walls of the aleurone layer accounted for the lower digestibility of the bran layers of raw rice since, on cooking, the cell walls of the aleurone layer were broken (see Plate 1), and this allows much greater enzymic breakdown of the bran protein. Saunders et al. (1972), in rat-feeding trials, reported an increase from 37 to $52 \%$ digestibility 
of wheat bran on treatment of the bran with cellulases; cellulase treatment of raw rice also increased its in vitro digestibility. These results support the point that increased protein digestibility of aleurone cells is dependent on breakage of the cell wall.

The reduction of the digestibility of the endosperm on cooking was found to be $11 \%$ (Table 2), in agreement with rat-feeding trials of Eggum et al. (1977), who obtained an $11.7 \%$ decrease in digestibility of the protein of milled IR-32 rice on cooking, compared with a $7.4 \%$ decrease (we obtained a $7 \%$ decrease, Table 2 ), in digestibility of the protein of brown rice as a result of cooking. The reason for the smaller reduction in digestibility of brown rice on cooking was due to an increase in the digestibility of the aleurone layer plus grain coat and the embryo, which partially compensates for the decreased digestibility of the endosperm brought about by cooking.

The results obtained in this in vitro study are also comparable to the results of in vivo studies with milled IR-32 and IR-480 rice on Filipino children (Roxas et al. 1979) and on Peruvian children (Maclean et al. 1978). While the value in Table 2 for the cooked endosperm $(70 \% \mathrm{~N}$ digested) is in reasonable agreement with that of Roxas et al. (1979) and Maclean et al. (1978) (apparent digestibilities of 66 and $67 \%$ respectively), the more important point is that the same trends are observed for the digestibilities of IR-32 rice, IR-480 rice and casein between in vivo and in vitro results.

It must be remembered that by slight modification of the in vitro conditions, an increase or decrease of $10 \%$ in the solubilized $\mathrm{N}$ can be obtained (Table 2). However, the important feature of an in vitro technique, which is fulfilled in this case, is that it shows the same changes in digestibility for different protein sources as those obtained using in vivo digestion techniques. Furthermore, it is highly desirable when comparing two protein sources that the relative changes of amino acids digested be similar using in vivo and in vitro techniques. This additional criterion is also satisfied with this in vitro technique as shown by comparing the changes in amino acid composition of the digests from cooked IR-32 rice as compared with raw IR-32 rice (Table 3) with the results of Tanaka et al. (1978) on the amino acid composition of cooked IR-32 rice and faecal protein. The digest of cooked rice (Table 3) contains more arginine (plus ornithine), aspartic acid, glycine and tyrosine and less glutamic acid, cystine, isoleucine and serine than does IR-32 brown rice. In general, these changes agree with those obtained by Tanaka et al. (1978), on the assumption that a positive change in one amino acid in the faecal protein corresponds with a negative change observed in the digest. We therefore conclude that the in vitro technique used here is a satisfactory method (and easier to use than in vivo methods) for the determination of the digestibility of rice and probably of protein sources in general.

The reason for the decreased digestibility of endosperm protein caused by cooking (Table 2 and Tanaka et al. (1978)) is still unclear. The cyanoethylation experiment (see p. 509), showed quite clearly that no isopeptide bonds were present in the protein of uncooked or cooked rice. The results in Table 3 show that, whereas the digest from uncooked rice contains the same amount of cystine as brown rice itself, that from cooked rice contains less cystine. This could possibly be due to breakdown of cystine in the intact protein in situ due to boiling. Alternatively, it is likely that proteolytic digestion of cooked (but not raw) rice is less effective near cystine cross-links, leaving a core of protein that is not digested (Tanaka et al. 1978) and that this accounts for the decreased digestibility of cooked rice (Table 2). Clearly more work is needed on the chemistry of this interesting process.

The results in Table 2 show that the in vitro digestibility of the protein of cooked brown rice is not significantly less than that of cooked milled rice. Since the in vitro technique has been shown previously to give the same trends as the in vivo methods, it is clear that the digestibility of the protein of cooked brown rice is about the same as that of cooked milled rice. It would therefore be advantageous for the millions of people in South and South-east 





Asia for whom rice is a staple food, to consume brown rather than milled rice, in order to benefit from the three times greater vitamin content (Juliano, 1972) and lipid content (Bradbury \& Collins, 1982), as well (for IR-32) as the $16 \%$ increase in protein content and the $20-25 \%$ increase in lysine content (Bradbury et al. $1980 a, b$ ).

The authors wish to thank Dr B. O. Juliano of IRRI for useful discussions and the Australian National University Microanalytical Unit for the nitrogen analyses.

\section{REFERENCES}

Akeson, W. R. \& Stahman, M. A. (1964). Journal of Nutrition 83, 257-261.

Bjarnason, J. \& Carpenter, K. J. (1969). British Journal of Nutrition 23, 859-868.

Bjarnason, J. \& Carpenter, K. J. (1970). British Journal of Nutrition 24, 313-329.

Bradbury, J. H. \& Collins, J. G. (1982). Cereal Chemistry 59, 159-162.

Bradbury, J. H., Collins, J. G. \& Pyliotis, N. A. (1980a): Cereal Chemistry 57, 133-137.

Bradbury, J. H., Collins, J. G. \& Pyliotis, N. A. (1980b). Cereal Chemistry 57, 343-346.

Buchanan, R. A. \& Byers, M. (1969). Journal of the Science of Food and Agriculture 20, 364-367.

Büchmann, N. B. (1979). Journal of the Science of Food and Agriculture 30, 583-589.

Cagampang, G. B., Perdon, A. A. \& Juliano, B. O. (1976). Phytochemistry 15, 1425-1429.

Collins, J. G. (1981). Proteins and lipids of rice and an NMR study of the chemical structure of oligosaccharides.

PhD Thesis, Australian National University.

Davenport, H. W. (1961). Physiology of the Digestive Tract. Chicago: Year book Medical Publishers Inc.

Eggum, B. O., Ressurreccion, A. P. \& Juliano, B. O. (1977). Nutrition Reports International 16, 649.

Ford, J. E. \& Salter, D. N. (1966). British Journal of Nutrition 20, 843-860.

Hsu, H. W., Vavak, D. L., Satterlee, L. D. \& Miller, G. P. (1977). Journal of Food Science 42, $1269-1273$.

Juliano, B. O. (1972). In Rice Chemistry and Technology, Chap. 2 [D. F. Houston, editor]. St Paul, MN, USA: American Association of Cereal Chemists.

Maclean, W. C., Klein, G. L., de Romana, G. L., Massa, E. \& Graham, G. C. (1978). Journal of Nutrition 108, $1740-1747$.

Pereira, S. M., Begum, A. \& Juliano, B. O. (1981). Qualitas Plantarum-Plant Foods for Human Nutrition 31, 97-108.

Pisano, J. J., Finlayson, J. S. \& Peyton, M. P. (1969). Biochemistry 8, 871-876.

Rinderknecht, H., Renner, J. G., Douglas, A. P. \& Adham, N. F. (1978). Gastroenterology 75, $1083-1089$.

Roxas, B. V., Intengan, C. L. \& Juliano, B. O. (1979). Journal of Nutrition 109, 832-839.

Saunders, R. M., Connor, M. A., Edwards, R. H. \& Kohler, G. O. (1972). Cereal Chemistry 49, $436-442$.

Sawai, H. \& Morita, Y. (1968). Agricultural and Biological Chemistry 32, 76-80.

Tanaka, Y., Ressurreccion, A. P., Juliano, B. O. \& Bechtel, D. B. (1978). Agricultural and Biological Chemistry 42, 2015-2023.

Waibel, P. E. \& Carpenter, K. J. (1972). British Journal of Nutrition 27, 509-515.

EXPLANATION OF PLATE

Plate 1. Electron micrograph of part of a rice grain heated at $100^{\circ}$ in water for $30 \mathrm{~min}$. GC, grain coat; $\mathrm{Al}$, aleurone layer; E, endosperm; B, breaks in the aleurone cell walls brought about by the heat treatment. 